\title{
The claustrum of the bottlenose dolphin Tursiops truncatus (Montagu 1821)
}

\author{
Bruno Cozzi 1 *, Giulia Roncon ${ }^{1}$, Alberto Granato ${ }^{2}$, Maristella Giurisato ${ }^{1}$, Maura Castagna ${ }^{3}$, \\ Antonella Peruffo ${ }^{1}$, Mattia Panin ${ }^{1}$, Cristina Ballarin ${ }^{1}$, Stefano Montelli ${ }^{1}$ and Andrea Pirone ${ }^{4}$ \\ ${ }^{1}$ Department of Comparative Biomedicine and Food Science, University of Padova, Legnaro, Italy \\ 2 Department of Psychology, Catholic University, Milan, Italy \\ ${ }^{3}$ Department of Translational Research on New Technologies in Medicine and Surgery, University of Pisa, Pisa, Italy \\ ${ }^{4}$ Department of Veterinary Sciences, University of Pisa, Pisa, Italy
}

Edited by:

Brian N. Mathur, University of

Maryland School of Medicine, USA

Reviewed by:

Preston E. Garraghty, Indiana

University, USA

Stefan Huggenberger, University of

Cologne, Germany

${ }^{*}$ Correspondence:

Bruno Cozzi, Department of

Comparative Biomedicine and Food

Science, University of Padova, Viale

dell'Università 16, 35020 Legnaro, Italy

e-mail: bruno.cozzi@unipd.it
The mammalian claustrum is involved in processing sensory information from the environment. The claustrum is reciprocally connected to the visual cortex and these projections, at least in carnivores, display a clear retinotopic distribution. The visual cortex of dolphins occupies a position strikingly different from that of land mammals. Whether the reshaping of the functional areas of the cortex of cetaceans involves also modifications of the claustral projections remains hitherto unanswered. The present topographic and immunohistochemical study is based on the brains of eight bottlenose dolphins and a wide array of antisera against: calcium-binding proteins (CBPs) parvalbumin (PV), calretinin (CR), and calbindin (CB); somatostatin (SOM); neuropeptide Y (NPY); and the potential claustral marker Gng2. Our observations confirmed the general topography of the mammalian claustrum also in the bottlenose dolphin, although (a) the reduction of the piriform lobe modifies the ventral relationships of the claustrum with the cortex, and (b) the rotation of the telencephalon along the transverse axis, accompanied by the reduction of the antero-posterior length of the brain, apparently moves the claustrum more rostrally. We observed a strong presence of CR-immunoreactive (-ir) neurons and fibers, a diffuse but weak expression of CB-ir elements and virtually no PV immunostaining. This latter finding agrees with studies that report that PV-ir elements are rare in the visual cortex of the same species. NPY- and somatostatin-containing neurons were evident, while the potential claustral markers Gng2 was not identified in the sections, but no explanation for its absence is currently available. Although no data are available on the projections to and from the claustrum in cetaceans, our results suggest that its neurochemical organization is compatible with the presence of noteworthy cortical inputs and outputs and a persistent role in the general processing of the relative information.

Keywords: claustrum, bottlenose dolphin, calcium binding proteins, NPY, somatostatin, insular cortex

\section{INTRODUCTION}

Dolphins (Delphinidae) are carnivore marine mammals belonging to the Infraorder Odontoceti (toothed whales). Together with the Infraorder Mysticeti (baleen whales) toothed whales belong to the taxon Cetacea which is today grouped together with Artiodactyla (even-toed hooved mammals) into the single order Cetartiodactyla (Geisler and Uhen, 2005; Thewissen et al., 2007). This relationship may explain some of their anatomical conformities and common evolutionary adaptations with domestic animals like the cow and the pig (for general reference see Slijper, 1979). However the brain of dolphins possesses some strikingly unique features, including compression of the longitudinal axis and expansion of the temporal width, pronounced rotation along the transverse (inter-insular) axis, essential absence of the olfactory lobe and nerves, intense folding of the cerebral cortex accompanied by reduced thickness, and general uniformity of columnar organization in the different topographical areas. On the other hand, the virtual absence of a typical layer IV in cetaceans (for a comprehensive review see Manger, 2006) is common also to other Cetartiodactyla and Ungulates in general (Hof et al., 1999, 2000). Physiological studies on brain functions and internal connections are obviously restricted by ethical reasons and by the consequent limited number of published studies. However, a review of the available information suggests that functional localizations differ from terrestrial mammals (Oelschläger and Oelschläger, 2009). The visual cortex is not located in the occipital pole, but shifted dorsally and placed longitudinally, separated from the inter-hemispheric scissure by the peculiar paralimbic lobe, and accompanied laterally by the elongated acoustic cortex (Lende and Akdikmen, 1968; Kesarev and Malofeeva, 1969; for review see Morgane et al., 1986). Motor and somatosensory cortices are pushed rostrally almost entirely on the frontal aspect of the 
brain, in relation also to the particularly advanced position of the cruciate sulcus (Lende and Akdikmen, 1968; Kesarev and Malofeeva, 1969).

The claustrum is considered to be reciprocally connected to several cortical areas, and to possess direct involvement in the processing of sensorimotor information (Crick and Koch, 2005), with a special relationship to the visual cortex in the cat (Olson and Graybiel, 1980; Minciacchi et al., 1995) and monkey (Remedios et al., 2010). The topographic shift of the dolphin visual cortex to a location parallel to the inter-hemispheric cleft, and the profound modifications of several modalities of somatosensory inputs (i.e., related to the virtual absence of taste buds in the tongue, reduction of the hand, and disappearance of the hind limb) suggest possible functional adaptative modifications of the claustrum. The claustrum of dolphins (and cetaceans in general) has never been specifically described, although references to its position and relationship with the complex insular cortex and pocket (Jacobs et al., 1984) indicate a predominance of the infrainsular part, corresponding to the central core of the insular cortex in parasagittal section. In fact the same authors report that in the posterior and dorsal insular regions of the bottlenose dolphin (Tursiops truncatus), the claustrum is "either absent or present as a discontinuous cell band beneath the insular cortex", and in their study the diagrams show a close proximity, if not contiguity, of the ventral claustrum with the sylvian cleft in the more caudal extension (Jacobs et al., 1984). The contiguity of the cetacean claustrum with the cerebral cortex was noted by other authors in the harbor porpoise (Jelgersma, 1934) and reported in a comprehensive review (Jansen and Jansen, 1969).

In the present study we intend to investigate the topography and selected neurochemical characteristics of the claustrum in the bottlenose dolphin, the most widely studied member of the Family Delphinidae. The neurochemical organization of the claustrum, as defined by the expression of calcium-binding proteins (CBPs), selected modulators (neuropeptide Y, NPY; somatostatin, SOM), and the recognized claustral marker Gng2 (Mathur et al., 2009) may help understand whether this structure maintains in dolphins the organization now considered typical of terrestrial mammals, and whether its neurochemical characteristics are similar to those of other mammalian models.

\section{MATERIALS AND METHODS TISSUE SAMPLES}

In this study we used samples of the claustrum obtained from the brains of eight bottlenose dolphins (see Table 1) stored in

Table 1 | Details of the sampled bottlenose dolphins.

\begin{tabular}{lccccc}
\hline Specimen & Sex & Origin & Age (years)/length/weight & Formalin & Frozen \\
\hline ID \# 95 & F & wild & 11 (pregnant adult) $/ 285 \mathrm{~cm}$ & & $\mathrm{X}$ \\
ID \# 107 & M & captive & $9 / 250 \mathrm{~cm}$ & $\mathrm{x}$ & $\mathrm{x}$ \\
ID \# 110 & M & wild & $>2 / 190 \mathrm{~cm} / 74 \mathrm{~kg}$ & & $\mathrm{x}$ \\
ID \# 114 & M & captive & newborn $/ 115 \mathrm{~cm}$ & $\mathrm{x}$ & \\
ID \# 133 & F & captive & adult (age uncertain) $/ 248 \mathrm{~cm}$ & $\mathrm{x}$ & \\
ID \# 139 & M & captive & $12 / 268 \mathrm{~cm} / 198 \mathrm{~kg}$ & $\mathrm{x}$ & $\mathrm{x}$ \\
ID \# 146 & M & captive & $3.5 / 226 \mathrm{~cm}$ & $\mathrm{x}$ & \\
ID \# 159 & M & captive & $>40 / 328 \mathrm{~cm}$ & $\mathrm{x}$ &
\end{tabular}

the Mediterranean marine mammal tissue bank (MMMTB) of the University of Padova at Legnaro, Italy. The MMMTB is a CITES recognized (IT020) research center and tissue bank (Ballarin et al., 2005), sponsored by the Italian Ministry of the Environment and the University of Padova, with the aim of harvesting tissues from wild and captive cetaceans and distributing them to qualified research centers worldwide.

Tissue samples consisted of blocks approximately $1 \mathrm{~cm}$ thick, including the claustrum, surrounded by portions of the adjoining structures (extreme and external capsules, insular cortex, putamen), carefully dissected (Figure 1) during post-mortem procedures performed in the necropsy room of the Department of Comparative Biomedicine and Food Science of the University of Padova at Legnaro. Post-mortem delay before actual sampling varied between 18 and $40 \mathrm{~h}$. The samples were fixed by immersion in $4 \%$ buffered formalin, washed in phosphate saline buffer (PBS) $0.1 \mathrm{M}, \mathrm{pH} 7.4$ and subsequently either processed for paraffin embedding or frozen by immersion in liquid nitrogen-chilled isopentane at $-30^{\circ} \mathrm{C}$. Sections were cut either with a microtome $(6 \mu \mathrm{m})$ or a cryostat $(20 \mu \mathrm{m})$ and subsequently processed for immunohistochemistry (see below). For each tissue block, one section out of ten was treated for Nissl stain for general outline, reference and topography.

\section{IMMUNOHISTOCHEMISTRY}

A rabbit polyclonal anti-calretinin (CR) antibody (sc-50453; Santa Cruz Biotech., Inc., Santa Cruz, CA; dilution 1:200), a mouse monoclonal anti-parvalbumin (PV) antibody (Clone PA235, Cat. \# P-3171; Sigma-Aldrich, St. Louis, MO, USA; dilution

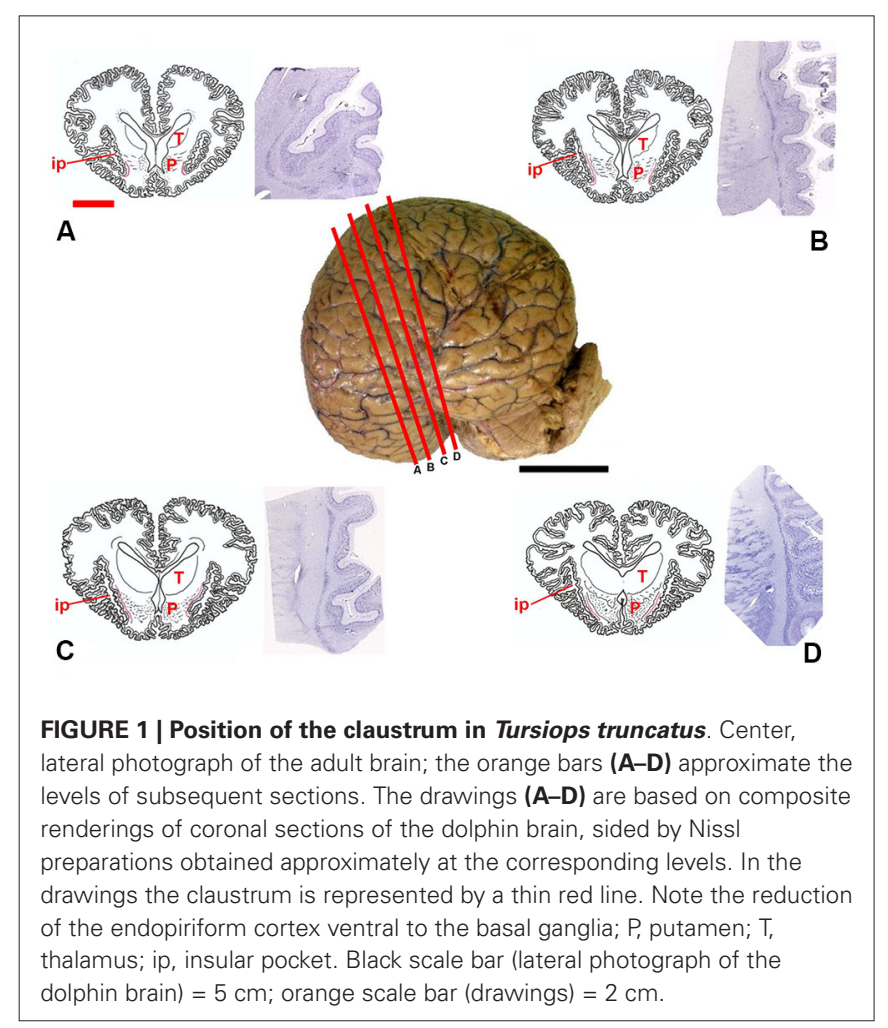


1:3000), a mouse monoclonal anti-calbindin-D-28K (CB) antibody (Clone CB-955, Cat. \# C9848, Sigma-Aldrich, St. Louis, MO, USA; dilution 1:3000), a rabbit polyclonal anti-CB-D-28K antibody (Cat. \# CB38A, Swant, Bellinzona, Switzerland; diluition 1:10000), a rabbit polyclonal anti-NPY antibody (ab30914; abcam; dilution 1:3000), a rabbit polyclonal anti-Gng2 antibody (HPA003534; Sigma-Aldrich, dilution 1:100), and a rabbit polyclonal anti-SOM antibody (ab103790; abcam; dilution 1:700) were used in this study. Epitope retrieval was carried out at $120^{\circ} \mathrm{C}$ in a pressure cooker for 5 min using a Tris/EDTA buffer $\mathrm{pH}$ 9.0. Sections were rinsed in PBS and incubated in $1 \% \mathrm{H}_{2} \mathrm{O}_{2}$-PBS for $10 \mathrm{~min}$, then pre-incubated in PBS with $0.3 \%$ Triton X-100 (TX) (Sigma-Aldrich, St. Louis, MO, USA) and $5 \%$ normal goat serum (Vector Labs, Burlingame, CA) to reduce non-specific staining. Sections were subsequently incubated overnight in a humid chamber at $4^{\circ} \mathrm{C}$ with the primary antibody diluted in PBS with $0.3 \%$ TX and 1\% normal goat serum. After several washings in PBS, sections were incubated for $1 \mathrm{~h}$ at room temperature with biotinylated goat anti-rabbit (for CR, NPY and SOM) or biotinylated goat anti-mouse secondary antibodies (for PV and CB) (Vector Labs, Burlingame, CA), diluted 1:300 in PBS. Sections were then washed for $3 \times$ $10 \mathrm{~min}$ in PBS, and incubated for $1 \mathrm{~h}$ at room temperature in avidinbiotin-horseradish peroxidase complex (PK-6100; Vector Labs, Burlingame, CA). After washing for $3 \times 10 \mathrm{~min}$ in Tris/HCl ( $\mathrm{pH}$ 7.6), peroxidase activity was detected by incubation in a solution of $0.125 \mathrm{mg} / \mathrm{ml}$ diaminobenzidine (Sigma-Aldrich, St. Louis, MO, USA) and $0.1 \% \mathrm{H}_{2} \mathrm{O}_{2}$ in the same buffer for $10 \mathrm{~min}$ or by a VIP substrate Kit for peroxidase (Cat. \# SK-4600, Vector Labs, Burlingame, CA).

The amino acid sequence of the proteins investigated in this article in the claustrum of Tursiops truncatus were compared with those of other mammals (and especially the rat). For this aim we used the Ensembl genomic database. ${ }^{1}$ The sequence of NPY, SOM, CB and CR is shared for over 93\%, whereas correspondence for Gng2 and PV is over 70\%. The specificity of the immunohistochemical staining was tested in repeated trials as follows: substitution of either the primary antibody, the anti-rabbit or anti-mouse IgG, or the ABC complex by PBS or non-immune serum. Under these conditions the staining was abolished.

\section{RESULTS}

\section{GENERAL TOPOGRAPHY AND SHAPE}

Based on the examinations of macroscopic slices of the brain, followed by analysis of Nissl-stained sections, the claustrum was detected in all the examined specimens, including newborns. The topography of the claustrum observed in our experimental series reflects the general orientation of the dolphin brain, in which the lateral (temporal) lobes grow considerably, and the lower (partially olfactory) divisions of the telencephalon are reduced. The position of the claustrum was clearly identified lateral to the conspicuous putamen and medial to the insular formation and relative insular pocket (Figure 1).

In Nissl-stained sections the claustrum appeared thin (not thicker than 1-2 mm) and dorso-ventrally elongated (up to

\footnotetext{
${ }^{1}$ www.ensembl.org
}

$3.5 \mathrm{~cm}$ ), without an evident endopiriform root as commonly found in terrestrial mammals. The ventralmost limits of the claustrum apparently touch the insular cortex with virtual disappearance of the capsula extrema.

\section{IMMUNOHISTOCHEMICAL DATA Calretinin}

In our experimental series, we observed a strong presence of CR-immunoreactive (-ir) neurons and fibers, both in paraffinembedded (Figures 2A-E) and frozen sections (Figures 2F, G). Positive cells appeared as mono- and bi-polar small (approx. $10 \mu \mathrm{m})$ neurons, with a round or fusiform soma. The morphology of CR-ir neurons in the claustrum was very different from that of the typical CR-ir neurons in the cortical columns of the adjacent insula (Figure 2E).

The distribution of CR-ir elements (Figures $2 \mathbf{H}-\mathbf{J}$ ) did not show any specific segregation and the neurons were diffuse in all the parts of the claustrum, although immunostained cells were scarcer at its dorsal and ventral extremities.

\section{Calbindin}

The examined sections showed a diffuse but weak expression of $\mathrm{CB}$-ir elements (Figures 3A-C). The few positive elements displayed a small (approx. $10 \mu \mathrm{m}$ ) mono- or bipolar soma. Positive fibers were evident throughout the claustrum.

\section{Parvalbumin}

The immunostaining for PV revealed no positive cell or fiber in the claustrum of all the animals examined.

\section{Neuropeptide $Y$}

The whole length of the claustrum is crossed by a mesh of NPY-ir beaded nerve fibers (Figures 4A, B), with some unipolar, pseudounipolar, and multipolar small-medium (15-20 $\mu \mathrm{m})$ neurons (Figures 4C, D). In cryostat cut sections some of these neurons displayed a well-ramified dendrite arborization (Figures 4E, F). Also the distribution of NPY-ir elements (Figures 4G-I) did not show any specific segregation, although immunostained cells were scarcer at the dorsal and ventral extremities of the claustrum.

\section{Somatostatin}

In our experimental series, we identified a few SOM-ir neurons in the claustrum (Figure 5). Immunostained elements appeared either as slender bipolar neurons or spherical, with medium dimensions (approx. 20-25 $\mu \mathrm{m}$ ). Fibers were rare.

\section{Gng2}

In our experimental series the claustral marker Gng2 was not identified in any cell or fiber of the claustrum or adjacent brains structures.

\section{DISCUSSION}

The position and relationships of the claustrum in the bottlenose dolphin described here is based on the analysis of macroscopic brain slices and Nissl stained sections. The location of the claustrum (Figure 6) reflects the changes in the general outline of the 


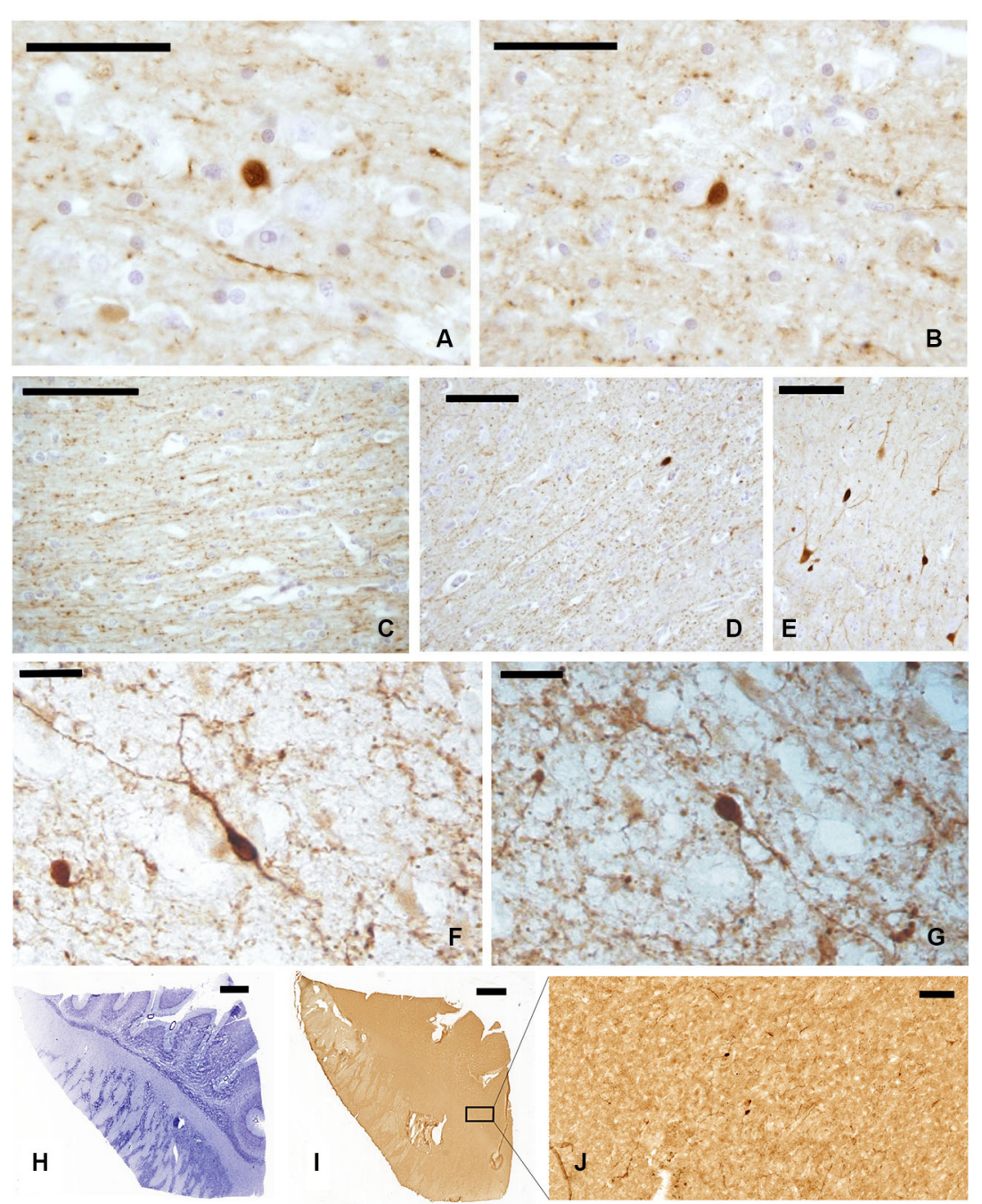

FIGURE 2 | CR-ir neurons and fibers in the claustrum. (A-D) Images derive from paraffin-embedded sections. (A, B) Small unipolar neurons surrounded by beaded fibers; (C, D) several CR-ir beaded fibers cross the whole length of the claustrum. (E) CR-ir neurons in the insular cortex. (F, G) Immunostained neurons in frozen sections; $(\mathbf{H}-\mathbf{J})$ localization of CR-ir neurons in whole sections ((H) Nissl stain, (I-J) immunocytochemistry); $\mathbf{J}$ represent an enlargement of the black rectangle in I Scale bars: $\mathbf{A}, \mathbf{B}=50 \mu \mathrm{m} ; \mathbf{C}, \mathbf{D}, \mathbf{E}, \mathbf{J}=$ $100 \mu \mathrm{m} ; \mathbf{F}, \mathbf{G}=20 \mu \mathrm{m} ; \mathbf{H}, \mathbf{I}=2 \mathrm{~mm}$.
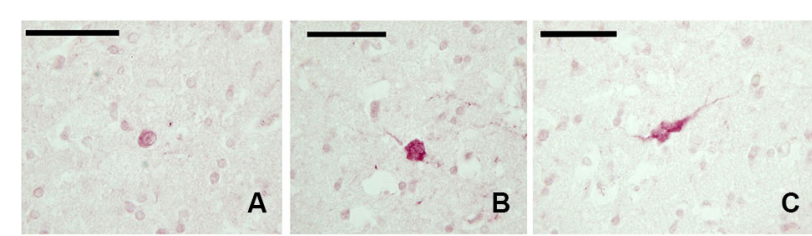

FIGURE 3 | CB-ir neurons in the claustrum. (A-C) Immunoreactive neurons in paraffin-embedded sections. Scale bars etc.

brain and consequently the modifications of its internal organization and topography. The absence of a complete endopiriform cortex as such (due to the lack of olfactory bulbs and related structures) limits the development of the so-called "endopiriform" part of the claustrum, and modifies its ventral outline.
The rostro-ventral part of the dolphin claustrum surrounds the ventral borders of the insular pocket, but shows no medial projections towards the midsagittal plane as in terrestrial mammals including man. The extreme reduction of the Ammon's horn and the hippocampal formation in general (Morgane et al., 1982), sensibly changes the disposition of ventro-lateral structures in the temporal lobe, and their reciprocal relationships. In man and other primates the caudalmost part of the claustrum terminates dorsal to the tail of the caudate nucleus and the hippocampus. This latter disposition is absent in the dolphin, in which the pronounced rotation of cerebral components along the transverse (inter-insular) axis (Figure 1; for detailed description and an interpretation see Morgane et al., 1980), and the reduction of olfaction-related limbic structures places the caudal extremity of the claustrum more anteriorly (see Figure 6). In a dated but well known review on the cetacean nervous system (Jansen and Jansen, 


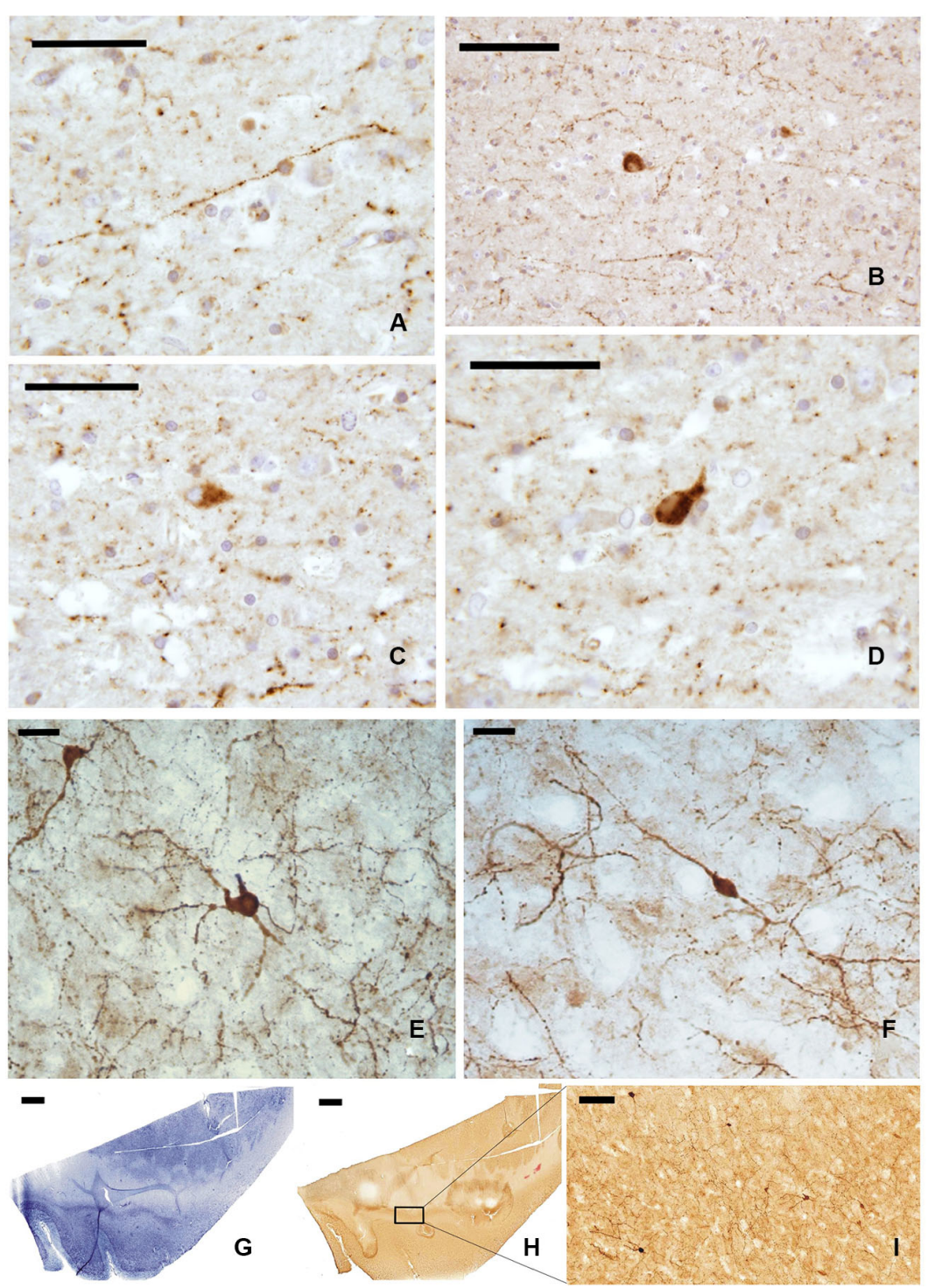

FIGURE 4 | NPY-ir fibers (A, B) and neurons (C, D) in paraffin-embedded sections of the claustrum; (E, F) NPY positive neurons in frozen sections; (G-I) localization of NPY-ir neurons in whole sections ((G) Nissl stain,
(H-I) immunocytochemistry); I represent an enlargement of the black rectangle in $\mathbf{H}$. Scale bars $=\mathbf{A}, \mathbf{C}, \mathbf{D}=50 \mu \mathrm{m} ; \mathbf{B}, \mathbf{I}=100 \mu \mathrm{m} ; \mathbf{E}, \mathbf{F}=20 \mu \mathrm{m}$; $\mathbf{G}, \mathbf{H}=2 \mathrm{~mm}$.
1969), it was noted that "the claustrum extends rostrolaterally beyond the limits of the putamen", with reference to the harbor porpoise (Jelgersma, 1934). The disposition of the claustrum that we describe here in Tursiops truncatus overlaps what reported for the common dolphin Delphinus delphis, at least based on a series of transverse sections of the brain (Pilleri et al., 1980).

Our data confirm what was reported in the drawings of the seminal paper on the bottlenose dolphin insula by Jacobs et al. (1984), in which the ventral extremity of the claustrum is attached to the insular cortex and the opercular gyri at the level of the insular pocket. We also noted contiguity between the insular cortex and the ventral extremity of the claustrum. We emphasize this topographical relationship in view of its ontogenetic significance for the origin of the claustrum. As well known, the claustrum may derive from (a) the putamen and basal ganglia; (b) the insular cortex; or possibly (c) a combination of both (Edelstein and Denaro, 2004). A recent study (Pirone et al., 2012), performed on post-mortem human brains, identified the presence of a potential claustral marker, the protein Gng2, formerly developed in rodents (Mathur et al., 2009), in the insular cortex and claustrum, but not in the putamen, thus suggesting a possible common origin of the former two structures. There is presently no information on how much the structure of Gng2 is conservative among mammals, and the eventual presence of different isoforms of this protein in cetaceans may explain the lack of immunoreactivity in our experimental series. However, contiguity between cortex and claustrum, as we observed in the bottlenose dolphin, may reinforce the insular hypothesis. 


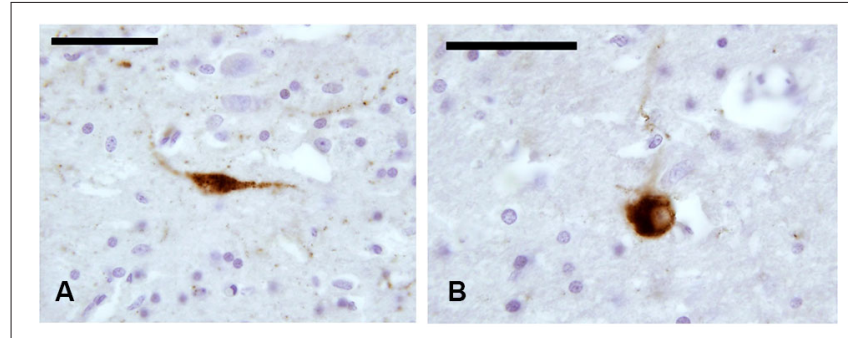

FIGURE 5 | SOM-ir fibers and neurons in the claustrum. (A-B) Images from paraffin-embedded sections. Scale bars etc.

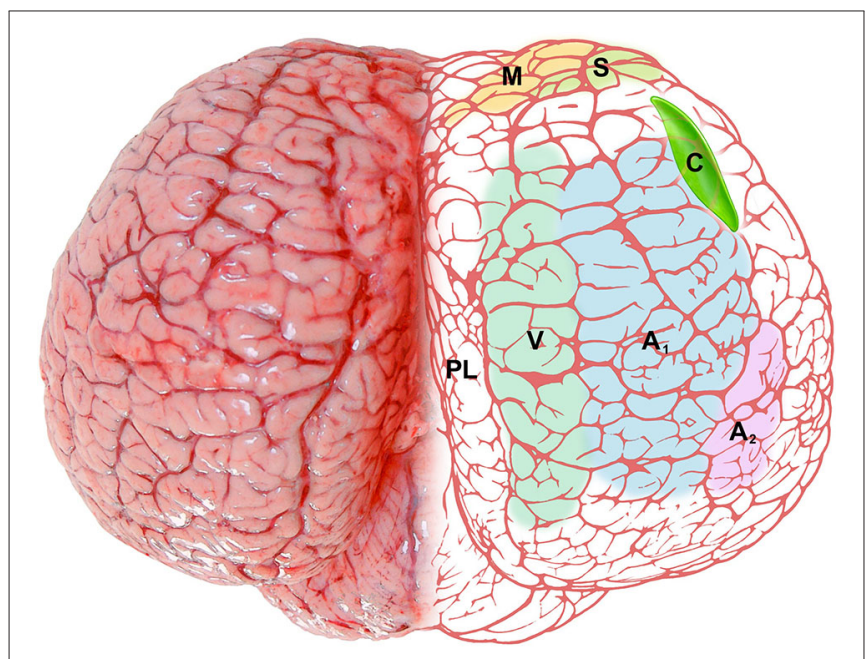

FIGURE 6 | Schematic representation of the claustrum (C, bright green) of the bottlenose dolphin shown through the dorsal aspect of the brain. The pale colors on the right side represent functional areas of the cortex: M (yellow), motor cortex; S (green), somatosensory cortex; $V$ (gray-green), visual cortex; $A_{1}$ (pale blue), primary auditory cortex; $A_{2}$ (pale pink), secondary auditory cortex; PL (no color), paralimbic lobe.

The presence of CBPs in the claustrum has been described in several mammalian species (Reynhout and Baizer, 1999; Ángeles Real et al., 2003; Wojcik et al., 2004; Rahman and Baizer, 2007), and a recent detailed study reports the distribution of PV in the human claustrum (Hinova-Palova et al., 2013). Former studies on the distribution of CBPs in the auditory and visual cortex of the bottlenose dolphin (Glezer et al., 1995, 1998) identified only very few PV-ir neurons, contrarily to what observed in the macaque Macaca fascicularis, in which PV was present or even prevalent in both systems. Furthermore, PV-ir neurons in the visual cortex of selected cetacean species were scarce except in layers IIIc/V and VI (Glezer et al., 1993). On the other hand, the GABA component seems not different between cetaceans and terrestrial mammals (Garey et al., 1989). Our data indicate that PV is not expressed in the claustrum of the bottlenose dolphin, a fact that may be related to the paucity of PV-ir neurons in the visual cortex of the same species described in the reports cited above. Considering that the PV amino acid sequence in dolphins shows a 70\% identity with the corresponding protein of terrestrial mammals, additional studies are required to further clarify this issue and its important implications in terms of claustro-visual projections. However we'd like to emphasize that our experimental procedures were performed under the same conditions applied in our laboratory to the primate claustrum in which a clear, well evident presence of a network of PV-containing elements was observed (data not shown), even when the brains suffered a post-mortem interval prior to sampling possibly longer than that of the bottlenose dolphins described here.

CR-ir neurons were described in the visual cortex of Tursiops truncatus (Glezer et al., 1992) and CR- and CB-ir neurons were identified especially in the auditory system of the same species (Reynhout and Baizer, 1999). In our series mono- or bi-polar neurons CR-ir were easily identified in the claustrum, and a few CB-ir neurons were also evident. The dorsal claustrum receives important visual projections from the occipital cortex in the cat (LeVay and Sherk, 1981), while the visual claustrum is instead ventral in primates (Remedios et al., 2010). The apparent reduction of the ventral part of the claustrum that takes place in the bottlenose does not imply curtailed visual projections, but may simply reflect a different topography of visual inputs/outputs as reported in other species. We emphasize here that the dolphin visual cortex shifts dorsally (see Figure 6), and a re-shaping of the internal organization of the claustrum may be plausible, with the visual domains potentially moving dorsally within the nucleus. The visual cortex of the dolphins shows a specific organization, containing both a heterolaminar part/component, with an incipient layer IV, and a homolaminar one, where layer IV is absent, as elsewhere in the cortex (Morgane et al., 1988), a feature typical of Cetartiodactyla (Hof et al., 1999, 2000). The mostly agranular visual cortex of the bottlenose dolphin has been discussed in details (Garey et al., 1985; Morgane et al., 1990), but its projections remain undetected. In a retrograde tracer study performed on Phocoena phocoena (Revishchin and Garey, 1990), the visual cortex was found to project to the lateral geniculate nucleus and inferior pulvinar, but no connection was precisely identified outside the thalamus. We note here that PV-ir elements are particularly abundant in layer IV of the somatosensory and auditory cortices of several mammalian orders (Sherwood et al., 2009), but CR and CB are the predominant CBPs in the Cetartiodactyla cortex (Hof et al., 1999, 2000), lacking layer IV. Our data indicate that in the bottlenose dolphin CR is the prevalent CBP in the claustrum, thus suggesting its potential role for reciprocal claustro-cortical connections.

The cellular types that we illustrate here correspond to those described in other species (for review see Edelstein and Denaro, 2004). NPY and SOM are expressed in neurons of the primate (Smith et al., 1985) and rodent claustrum (Kowiański et al., 2008). Due to the plausible common origin of claustrum and insular cortex (Pirone et al., 2012), we can only speculate that claustral and cortical interneurons may play similar functional roles. In the neocortex, Martinotti cells, which target the apical tuft of pyramidal dendrites, express SOM (Markram et al., 2004). Similarly, NPY expressing neurons are able to modulate $\mathrm{Ca}^{2+}$ dependent currents in the distal dendrites in pyramidal neurons (Hamilton et al., 2013). On the contrary, PV interneurons mainly 
target the soma and proximal dendrites of principal neurons (Markram et al., 2004). Therefore, given the presence of NPY and SOM interneurons in the dolphin claustrum, along with the absence of PV, it is possible that the cetacean claustrum might display a prevalence of interneurons with putative synapses onto distal dendrites of projecting neurons. The functional significance of this peculiar feature would deserve further examination.

Our observations confirmed the general outline of the mammalian claustrum also in the bottlenose dolphin, even if the reduction of the piriform lobe modifies the ventral relationships with the cortex.

Although no data are available on the projections to and from the claustrum in cetaceans, our results provide evidence that its neurochemical organization is compatible with the presence of cortical inputs and outputs and a persistent role in the general processing of the relative information. PV-containing interneurons, absent in the claustrum of the bottlenose dolphin, are important fast-spiking elements in the cortex (Moore et al., 2010) and neostriatum (Tepper et al., 2004). Whether the particular display of CBPs in the dolphin claustrum may be functionally related to the structural organization of the cortex (Morgane and Jacobs, 1972; Kern et al., 2011); to the shift in the functional areas (Oelschläger and Oelschläger, 2009); to the virtual absence of binocular vision and the fact that the retina projects almost exclusively to the contralateral hemisphere (Ridgway, 1990; Tarpley et al., 1994); or to the peculiar mono-hemispheric sleep pattern (Mukhametov et al., 1977; see Lyamin et al., 2008 for a recent review), awaits further verification.

\section{ACKNOWLEDGMENTS}

The Authors willingly acknowledge the precious contribution of Massimo Demma who drew the three-dimensional image of the dolphin brain represented in Figure 6.

\section{REFERENCES}

Ángeles Real, M., Dávila, J. C., and Guirado, S. (2003). Expression of calciumbinding proteins in the mouse claustrum. J. Chem. Neuroanat. 25, 151-160. doi: 10.1016/s0891-0618(02)00104-7

Ballarin, C., Papini, L., Bortolotto, A., Butti, C., Peruffo, A., Sassu, R., et al. (2005). An on-line bank for marine mammals of the Mediterranean Sea and adjacent waters. Hystrix It. J. Mamm. 16, 127-133. doi: 10.4404/hystrix-16.2-4350

Crick, F. C., and Koch, C. (2005). What is the function of the claustrum? Philos. Trans. R. Soc. Lond. B Biol. Sci. 360, 1271-1279. doi: 10.1098/rstb.2005.1661

Edelstein, L. R., and Denaro, F. J. (2004). The claustrum: a historical review of its anatomy, physiology, cytochemistry and functional significance. Cell. Mol. Biol. (Noisy-le-grand) 50, 675-702. doi: 10.1170/T558

Garey, L. J., Takás, J., Revishchin, A. V., and Hámori, J. (1989). Quantitative distribution of GABA-immunoreactive neurons in cetacean visual cortex is similar to that in land mammals. Brain Res. 485, 278-284. doi: 10.1016/00068993(89)90571-4

Garey, L. J., Winkelmann, E., and Brauer, K. (1985). Golgi and Nissl studies of the visual cortex of the bottlenose dolphin. J. Comp. Neurol. 240, 305-321. doi: 10. 1002/cne.902400307

Geisler, J. H., and Uhen, M. D. (2005). Phylogenitic relationships of extinct cetartiodactyls: results of simultaneous analyses of molecular, morphological, and stratigraphic data. J. Mammal. Evol. 12, 145-160. doi: 10.1007/s10914-0054963-8

Glezer, I. I., Hof, P. R., Istomin, V. V., and Morgane, P. J. (1995). “Comparative immunocytochemistry of calcium-binding protein-positive neurons in visual and auditory systems of cetacean and primate brains," in Sensory Systems of
Aquatic Mammals, eds R. A. Kastelein, J. A. Thomas and P. E. Nachtigall (The Netherlands: De Spil Publishers, Woerden), 477-513.

Glezer, I. I., Hof, P. R., Leranth, C., and Morgane, P. J. (1993). Calcium-binding protein-containing neuronal populations in mammalian visual cortex: a comparative study in whales, insectivores, bats, rodents and primates. Cereb. Cortex 3, 249-272. doi: 10.1093/cercor/3.3.249

Glezer, I. I., Hof, P. R., and Morgane, P. J. (1992). Calretinin-immunoreactive neurons in the primary visual cortex of dolphin and human brains. Brain Res. 595, 181-188. doi: 10.1016/0006-8993(92)91047-i

Glezer, I. I., Hof, P. R., and Morgane, P. J. (1998). Comparative analysis of calcium-binding protein-immunoreactive neuronal populations in the auditory and visual systems of the bottlenose dolphin (Tursiops truncatus) and the macaque monkey (Macaca fascicularis). J. Chem. Neuroanat. 15, 203-237. doi: 10.1016/s0891-0618(98)00022-2

Hamilton, T. J., Xapelli, S., Michaelson, S. D., Larkum, M. E., and Colmers, W. F. (2013). Modulation of distal calcium electrogenesis by neuropeptide Y receptors inhibits neocortical long-term depression. J. Neurosci. 33, 11184-11193. doi: 10. 1523/jneurosci.5595-12.2013

Hinova-Palova, D. V., Edelstein, L., Landzhov, B. V., Braak, E., Malinova, L. G., Minkov, M., et al. (2013). Parvalbumin-immunoreactive neurons in the human claustrum. Brain Struct. Funct. doi: 10.1007/s00429-013-0603-x. [Epub ahead of print].

Hof, P. R., Glezer, I. I., Condé, F., Flagg, R. A., Rubin, M. B., Nimchinsky, E. A., et al. (1999). Cellular distribution of the calcium-binding proteins parvalbumin, calbindin, and calretinin in the neocortex of mammals: phylogenetic and developmental patterns. J. Chem. Neuroanat. 16, 77-116. doi: 10.1016/s08910618(98)00065-9

Hof, P. R., Glezer, I. I., Nimchinsky, E. A., and Erwin, J. M. (2000). Neurochemical and cellular specializations in the mammalian neocortex reflect phylogenetic relationships: evidence from primates, cetaceans, and artiodactyls. Brain Behav. Evol. 55, 300-310. doi: 10.1159/000006665

Jacobs, M. S., Galaburda, A. M., McFarland, W. L., and Morgane, P. J. (1984). The insular formations of the dolphin brain: quantitative cytoarchitectonic studies of the insular component of the limbic lobe. J. Comp. Neurol. 225, 396-432. doi: 10.1002/cne.902250307

Jansen, J., and Jansen, J. K. S. (1969). "The nervous system of cetacean," in The Biology of Marine Mammals, ed H. T. Andersen (New York, USA: Academic Press), 175-252.

Jelgersma, G. (1934). Das Gehirn der Wassersäugetiere. Eine Anatomische Untersuchung. Leipzig: Von Johann Ambrosium Bart Verlag, 82-91.

Kern, A., Siebert, U., Cozzi, B., Hof, P. R., and Oelschläger, H. H. (2011). Stereology of the neocortex in Odontocetes: qualitative, quantitative and functional implications. Brain Behav. Evol. 77, 79-90. doi: 10.1159/000323674

Kesarev, V. S., and Malofeeva, L. I. (1969). Structural organization of the motor zone of the cerebral cortex in dolphins. Arkh. Anat. Gistol. Embriol. 56, 48-55.

Kowiański, P., Moryś, J. M., Dziewiatkowski, J., Wójcik, S., Sidor-Kaczmarek, J., and Moryś, J. (2008). NPY-, SOM- and VIP-containing interneurons in postnatal development of the rat claustrum. Brain Res. Bull. 76, 565-571. doi: 10.1016/j. brainresbull.2008.04.004

Lende, R. A., and Akdikmen, S. (1968). Motor field in cerebral cortex of the bottlenose dolphin. J. Neurosurg. 29, 495-499. doi: 10.3171/jns.1968.29.5.0495

LeVay, S., and Sherk, H. (1981). The visual claustrum of the cat. I. Structure and connections. J. Neurosci. 1, 956-980.

Lyamin, O. I., Manger, P. R., Ridgway, S. H., Mukhametov, L. M., and Siegel, J. M. (2008). Cetacean sleep: an unusual form of mammalian sleep. Neurosci. Biobehav. Rev. 32, 1451-1484. doi: 10.1016/j.neubiorev.2008.05.023

Manger, P. R. (2006). An examination of cetacean brain structure with a novel hypothesis correlating thermogenesis to the evolution of a big brain. Biol. Rev. Camb. Philos. Soc. 81, 293-338. doi: 10.1017/s1464793106007019

Markram, H., Toledo-Rodriguez, M., Wang, Y., Gupta, A., Silberberg, G., and Wu, C. (2004). Interneurons of the neocortical inhibitory system. Nat. Rev. Neurosci. 5, 793-807. doi: 10.1038/nrn1519

Mathur, B. N., Caprioli, R. M., and Deutch, A. Y. (2009). Proteomic analysis illuminates a novel structural definition of the claustrum and insula. Cereb. Cortex 19, 2372-2379. doi: 10.1093/cercor/bhn253

Minciacchi, D., Granato, A., Antonini, A., Tassinari, G., Santarelli, M., Zanolli, L., et al. (1995). Mapping subcortical extrarelay afferents onto primary somatosensory and visual areas in cats. J. Comp. Neurol. 362, 46-70. doi: 10.1002/cne. 903620104 
Moore, C. I., Carlen, M., Knoblich, U., and Cardin, J. A. (2010). Neocortical interneurons: from diversity, strength. Cell 142, 189-193. doi: 10.1016/j.cell. 2010.07.005

Morgane, P. J., Glezer, I. I., and Jacobs, M. S. (1988). Visual cortex of the dolphin: an image analysis study. J. Comp. Neurol. 273, 3-25. doi: 10.1002/cne. 902730103

Morgane, P. J., Glezer, I. I., and Jacobs, M. S. (1990). “Comparative anatomy of the visual cortex of the dolphin,” in Cerebral Cortex (Vol. 8B), eds E. G. Jones and A. Peters (New York, USA: Plenum Publishing Co.), 215-262.

Morgane, P. J., and Jacobs, M. S. (1972). "Comparative anatomy of the cetacean nervous system," in Functional Anatomy of Marine Mammals (Vol. 1), ed R. J. Harrison (London, UK: Academic Press), 117-244.

Morgane, P. J., Jacobs, M. S., and Galaburda, A. (1986). "Evolutionary morphology of the dolphin brain," in Dolphin Cognition and Behavior. A Comparative Approach, eds R. Schusterman, J. Thomas and F. Wood (Hillsdale, New Jersey: Lawrence Erlbaum Associates), 5-28.

Morgane, P. J., Jacobs, M. S., and McFarland, W. L. (1980). The anatomy of the brain of the bottlenose dolphin (Tursiops truncatus). Surface configuration of the telencephalon of the bottlenose dolphin with comparative anatomical observations in four other cetacean species. Brain Res. Bull. 5(Suppl. 3), 1-107. doi: 10.1016/0361-9230(80)90272-5

Morgane, P. J., McFarland, W. L., and Jacobs, M. S. (1982). The limbic lobe of the dolphin brain: a quantitative cytoarchitectonic study. J. Hirnforsch. 23, 465-552.

Mukhametov, L. M., Supin, A. Y., and Polyakova, I. G. (1977). Interhemispheric asymmetry of the electroencephalographic sleep pattern in dolphins. Brain Res. 134, 581-584. doi: 10.1016/0006-8993(77)90835-6

Oelschläger, H. H. A., and Oelschläger, J. S. (2009). "Brain," in Encyclopedia of Marine Mamamals (2nd Edn.), eds W. F. Perrin, B. Würsing and J. G. M. Thewissen (Amsterdam: Academic Press), 134-149.

Olson, C. R., and Graybiel, A. M. (1980). Sensory maps in the claustrum of the cat. Nature 288, 479-481. doi: 10.1038/288479a0

Pilleri, G., Peixun, C., and Zuohua, S. (1980). Concise Macroscopical Atlas of the Brain of the Common Dolphin (Delphinus delphis Linnaeus, 1758). Waldau-Berne Switzerland: Brain Anatomy Institute, University of Berne.

Pirone, A., Cozzi, B., Edelstein, L., Peruffo, A., Lenzi, C., Quilici, F., et al. (2012). Topography of Gng2- and NetrinG2-expression suggests an insular origin of the human claustrum. PLoS One 7:e44745. doi: 10.1371/journal.pone.0044745

Rahman, F. E., and Baizer, J. S. (2007). Neurochemically defined cell types in the claustrum of the cat. Brain Res. 1159, 94-111. doi: 10.1016/j.brainres.2007. 05.011

Remedios, R., Logothetis, N. K., and Kayser, C. (2010). Unimodal responses prevail within the multisensory claustrum. J. Neurosci. 30, 12902-12907. doi: 10. 1523/JNEUROSCI.2937-10.2010

Revishchin, A. V., and Garey, L. J. (1990). The thalamic projection to the sensory neocortex of the porpoise, Phocoena phocoena. J. Anat. 169, 85-102.
Reynhout, K., and Baizer, J. S. (1999). Immunoreactivity for calcium-binding proteins in the claustrum of the monkey. Anat. Embryol. (Berl) 199, 75-83. doi: $10.1007 / \mathrm{s} 004290050211$

Ridgway, S. H. (1990). “The central nervous system of the bottlenose dolphin," in The Bottlenose Dolphin, eds S. Leatherwood and R. R. Reeves (San Diego, USA: Academic Press), 69-97.

Sherwood, C. C., Stimpson, C. D., Butti, C., Bonar, C. J., Newton, A. L., Allman, J. M., et al. (2009). Neocortical neuron types in Xenarthra and Afrotheria: implications for brain evolution in mammals. Brain Struct. Funct. 213, 301-328. doi: 10.1007/s00429-008-0198-9

Slijper, E. J. (1979). Whales 2nd Edn. London: Hutchinson. 511pp.

Smith, Y., Parent, A., Kerkérian, L., and Pelletier, G. (1985). Distribution of neuropeptide $\mathrm{Y}$ immunoreactivity in the basal forebrain and upper brainstem of the squirrel monkey (Saimiri sciureus). J. Comp. Neurol. 236, 71-89. doi: 10. 1002/cne.902360107

Tarpley, R. Y., Gelderd, J. B., Bauserman, S., and Ridgway, S. H. (1994). Dolphin peripheral visual pathway in chronic unilateral ocular atrophy: complete decussation apparent. J. Morphol. 222, 91-102. doi: 10.1002/jmor.1052220109

Tepper, J. M., Koós, T., and Wilson, C. J. (2004). GABAergic microcircuits in the neostriatum. Trends Neurosci. 27, 662-669. doi: 10.1016/j.tins.2004.08.007

Thewissen, J. G. M., Cooper, L. N., Clementz, M. T., Bajpai, S., and Tiwari, B. N. (2007). Whales originated from aquatic artiodactyls in the Eocene epoch of India. Nature 450, 1190-1194. doi: 10.1038/nature06343

Wojcik, S., Dziewiatkowski, J., Spodnik, E., Ludkiewicz, B., Domaradzka-Pytel, B., Kowianski, P., et al. (2004). Analysis of calcium binding protein immunoreactivity in the claustrum and the endopiriform nucleus of the rabbit. Acta Neurobiol. Exp. (Wars) 64, 449-460.

Conflict of Interest Statement: The authors declare that the research was conducted in the absence of any commercial or financial relationships that could be construed as a potential conflict of interest.

Received: 25 January 2014; accepted: 10 March 2014; published online: 28 March 2014. Citation: Cozzi B, Roncon G, Granato A, Giurisato M, Castagna M, Peruffo A, Panin M, Ballarin C, Montelli S and Pirone A (2014) The claustrum of the bottlenose dolphin Tursiops truncatus (Montagu 1821). Front. Syst. Neurosci. 8:42. doi: 10.3389/fnsys. 2014.00042

This article was submitted to the journal Frontiers in Systems Neuroscience.

Copyright (C) 2014 Cozzi, Roncon, Granato, Giurisato, Castagna, Peruffo, Panin, Ballarin, Montelli and Pirone. This is an open-access article distributed under the terms of the Creative Commons Attribution License (CC BY). The use, distribution or reproduction in other forums is permitted, provided the original author(s) or licensor are credited and that the original publication in this journal is cited, in accordance with accepted academic practice. No use, distribution or reproduction is permitted which does not comply with these terms. 